\title{
Monitoring sample landslides in seismic areas: Camporaghena in Lunigiana
}

\author{
Alberto Pochini and Mario Allagosta \\ Dipartimento di Scienze della Terra, Università di Pisa, Italia
}

\begin{abstract}
As part of the research effort entitled «Vulnerabilità sismica dell'ambiente fisico» (Seismic vulnerability of the physical environment) of the GNDT-CNR (Gruppo Nazionale per la Difesa dai Terremoti del Consiglio Nazionale delle Ricerche - The National Group for Defense against Earthquakes of the National Research Council), a project for the monitoring of active landslides was initiated in several seismic areas, with the aim of following their evolution under static conditions as well as in the event of an earthquake.

The study, carried out with the collaboration of all Research Units of the SGL (Work sub-section) 1.3.2., has had

as its first focus the Camporaghena landslide near Massa in the Italian seismic region of Lunigiana/Garfagnana.
The research on this landslide aims to:
\end{abstract}

1) better define active landslides and subsequently determine their slip surfaces and the shape and dimensions of these latter;

2) precisely measure the physical and mechanical characteristics of the soil and rock involved;

3) institute real-time monitoring of the evolution of landslide phenomenon for the subsequent verification of the applicability of the adopted models and calculation codes.

Continuous monitoring of deformations was set up by means of an automated sampling system utilizing both conventional and experimental sensors. The current article presents the monitoring system's make up, the earliest measurements obtained and some preliminary results.

\section{Introduction}

The GNDT of the CNR, in its executive program of 1988-1989, initiated a research project on the study and modelling of sample unstable slopes with the goal of defining simplified and generalizable procedures which describe the behavior of unstable slopes under seismic forces. A pivotal concern of this research is the acquisition of data on events occurring both during, and as a consequence of, seismic activity.

Thus, in 1990 experimentation was begun on the unstable slope on which rests the town of Camporaghena (Comano, Massa) in the Lunigia-
na-Garfagnana seismic area of the northern Apennine mountains. Different aspects of the work was carried out through the collaborative efforts of each and every Research Unit of SGL 1.3.2, with varying competencies in geology, geotechnics and geophysics.

The project called for studies of the slope's geological structure and geomorphological characteristics. On the basis of the emerging profile, geognostic sampling sites were selected which seemed most suitable for determinations of the mechanical and physical features of the soil and the installation of real-time monitoring sensors to provide continuous data on the slope under static and seismic conditions. 


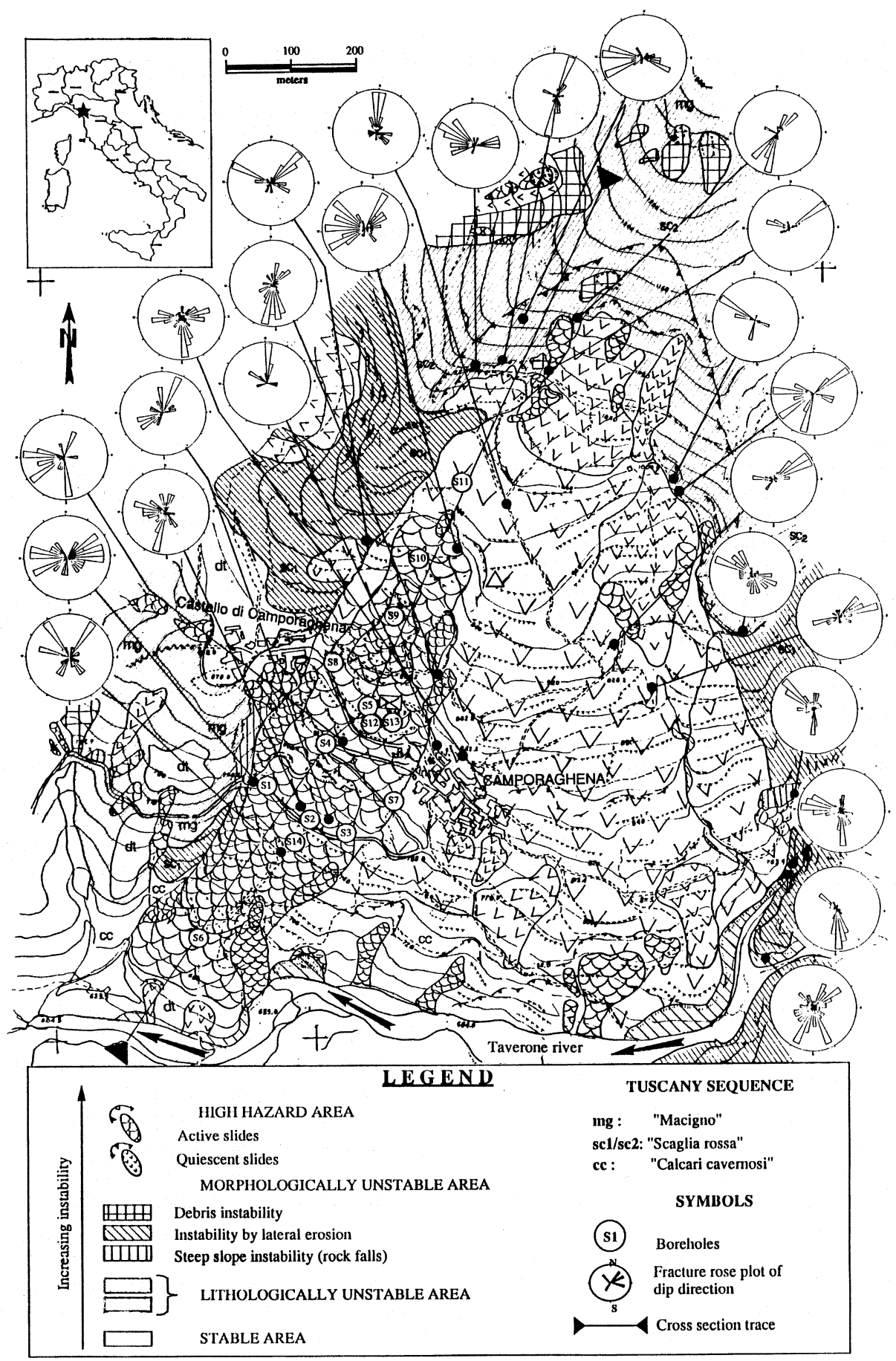

Fig. 1. Map of the landslide hazard with structural data and boreholes positions. 


\section{Profile of the Camporaghena landslide}

The landslide phenomenon encountered is quite complex and demonstrates several ongoing and potential instabilities which involve a rather wide area (roughly $0.35 \mathrm{sq}$. $\mathrm{km}$.). The overall phenomenon can be attributed to the combination of various movements of specific types, and definable as a rotational slump with several slip surfaces (Varnes, 1978). This same landslide has been studied with suitable conventional methods (Schuster and Krizek, 1978); that is, geomorphological and surface structural tests, photo-geological and photogrammetric analyses, geognostic and seismic refraction studies, inclinometer measurements, etc. The results obtained from these batteries are summarized in fig. 1, along with the areal distribution of the instabilities, and fig. 2, which is a representation of the area's cross-section as extrapolated from the data.

From the figures it are apparent that the slope was involved in an old slide of considerable size which is now quiescent and on which other more recent events have supervened. Moreover, some of these latter areas present clear signs of activity.

The rock formations belong to the non-metamorphic Tuscan Sequence, more specifically, those of the slope reveal «calcare cavernoso» (cc), «scaglia rossa» (sc) and «macigno» (mg), from depth to surface.

The «calcare cavernoso» formation contains dark gray small-celled limestone and dolomite of the upper, Noric-Raetic, Triassic age, with associated sedimentary breccias of varying origins dating back to the Tertiary age. These latter are made up of elements belonging to both the metamorphic and non-metamorphic Tuscan Sequence. The formation also includes local deposits of chalk. Its full thickness exceeds one hundred meters and the formation surfaces in the deep valley of the River Taverone.

The «scaglia rossa» rests in the lowest part of the slope with one member characterized by a preponderance of shaly facies, made up of multicolored shale interspersed with marl and marly and siliceous limestone (sc1). In the slope's upper portion there is a member with a prevalence of a marly limestone substrate ( $\mathrm{sc} 2$ ). This rock formation is from between the Lower Cretaceous (p.p.) and Oligocene ages. The landslide concerned almost exclusively the scaglia layermeasurements carried out at the level of lowest resistance revealed shear strength values $\phi$ from $22.5^{\circ}$ to $27.5^{\circ}$, and a cohesion of $c<4 \mathrm{KN} / \mathrm{m}^{2}$.

The «macigno» formation is principally of the quarzitic, feldspatic variety, alternating with shale and siltstone and dates from between the late Middle to Upper Oligocene age.

The studied area also contains Quaternary terrain made up of recent and current alluvion on the valley floor, detritus and top soil (dt.).

The lack of some elements of the Tuscan sequence, which has elsewhere been traced to stratigraphic gaps or laminations, may instead be due in this case to the diapiric phenomena documented in analogous situations in surrounding areas.

\section{The monitoring system}

The goal of installing the chosen monitoring system is the acquisition of data for precisely determining the fundamental characteristics of the development of the processes still active in the landslide, especially when subjected to a seismic event. The elements of this system deemed most suitable to the situation in hand are (Bruzzi, Pezzetti and Piccoli, 1986; Hanna, 1985; Pellegrino, 1986; Pilot, 1984; Ribacchi, 1986; Schuster and Krizek, 1978; Zaruba and Mencl, 1982): surface extensometers and multiple depth extensometers inserted into the probe bore, electrical piezometers, geophones and accelerometers.

The placement of each of the individual probes is diagrammed in fig. 3 , which also presents a schematic representation of the connections between these recording devices and the central data acquisition and recording terminal.

Continuous monitoring has therefore been carried out on both the surface of the landslide, by means of the Invar wire extensometer, and the deformations in the interior of the slope, measured by the depth wire extensometers. These latter experimental instruments can be simply described as being composed of a number of weights positioned at various depths and then bound to the surrounding matter. The same weights are also connected by means of steel wires to the surface-based measuring head. Thus, the degrees of deformation at the different weight 


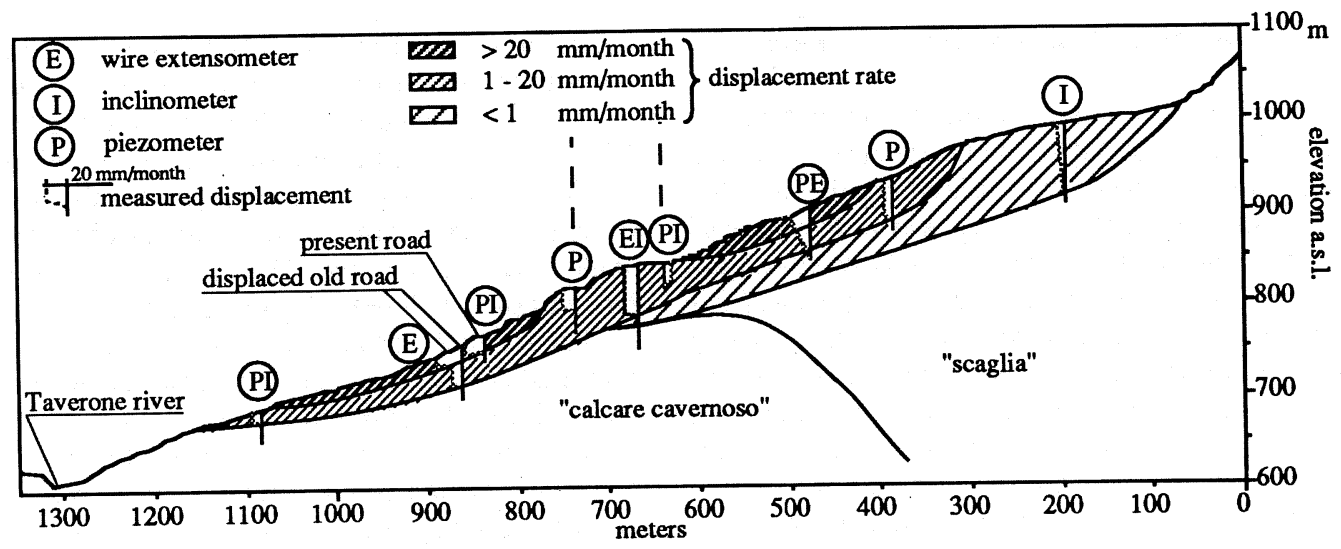

Fig. 2. Cross-section with displacement rates of surfaces slips.

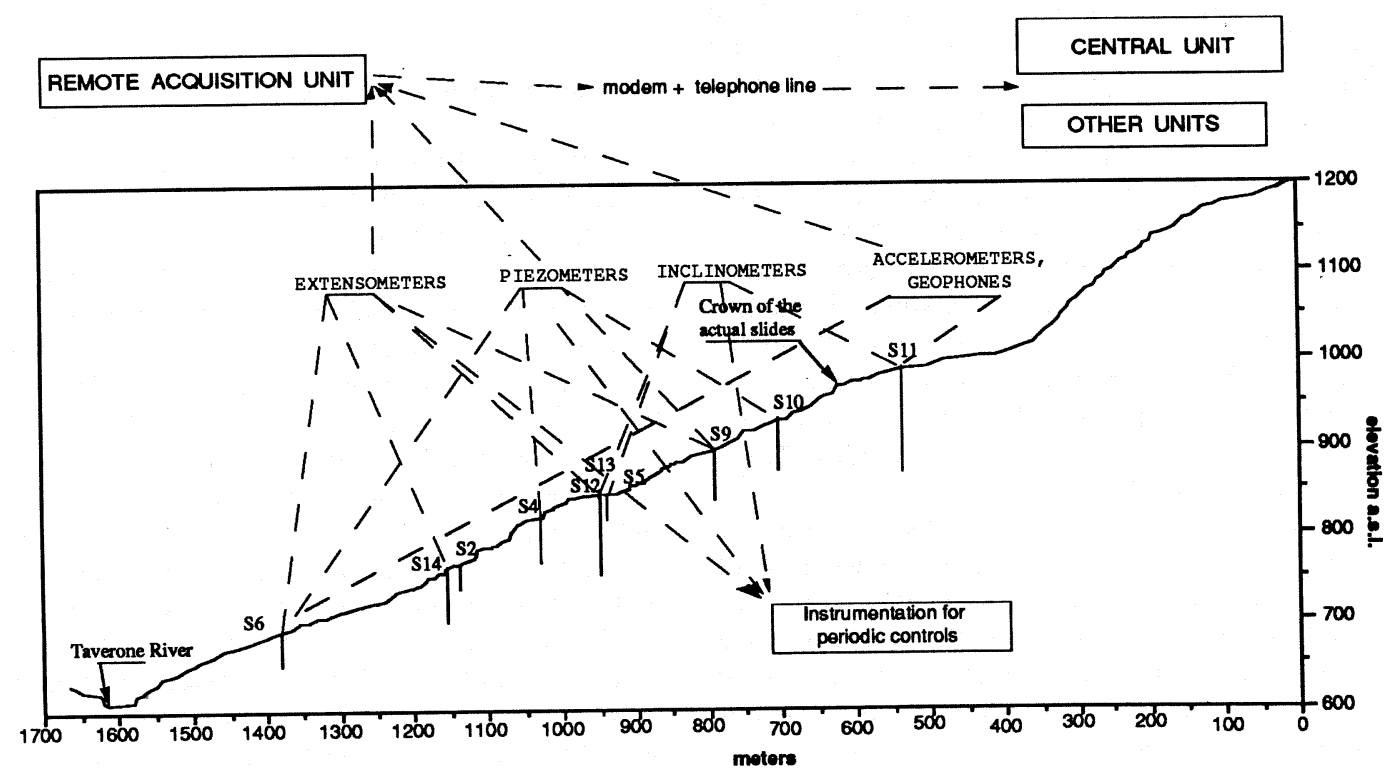

Fig. 3. Sketch of the instrumentation of Camporaghena landslide for periodic control and monitoring.

depths at any given moment are measured contemporaneously.

A part of this extensometric network has been fitted with mechano-voltaic transducers which sense displacements of the wires and convert them to graded electrical signals. Both the superficial and deep probe extensometers were positioned immediately above and below the displacement surfaces which had been revealed by the battery of inclinometric measurements, as well as by vernier analysis of periodic extensometric readings.

The electrical signals generated by the sensors are transmitted to the data acquisition and storage unit, as diagrammed in fig. 3 . The same unit collects the information arriving from the triaxial accelerometers and geophones set at varying altitudes along the landslide surface, and at differ- 
ent depths within its interior.

The storage unit has been realized through the application of numeric control technology in such a way as to insure the greatest flexibility and cost efficiency. It pilots the sensors, carries out a preliminary check of incoming data and stores them for transmission to the central calculation unit at the University of Pisa's Department of Earth Science.
The units have been programmed to pilot the sensors according to a preset threshold paradigm. That is, it performs the first data processing: the conversion of the impinging analogic information to digital and the manipulation of measures calculated from it, such as the rate of deformation and the amplitude of an acoustic signal. These, and other, parameters are then compared to the established threshold values for each and the
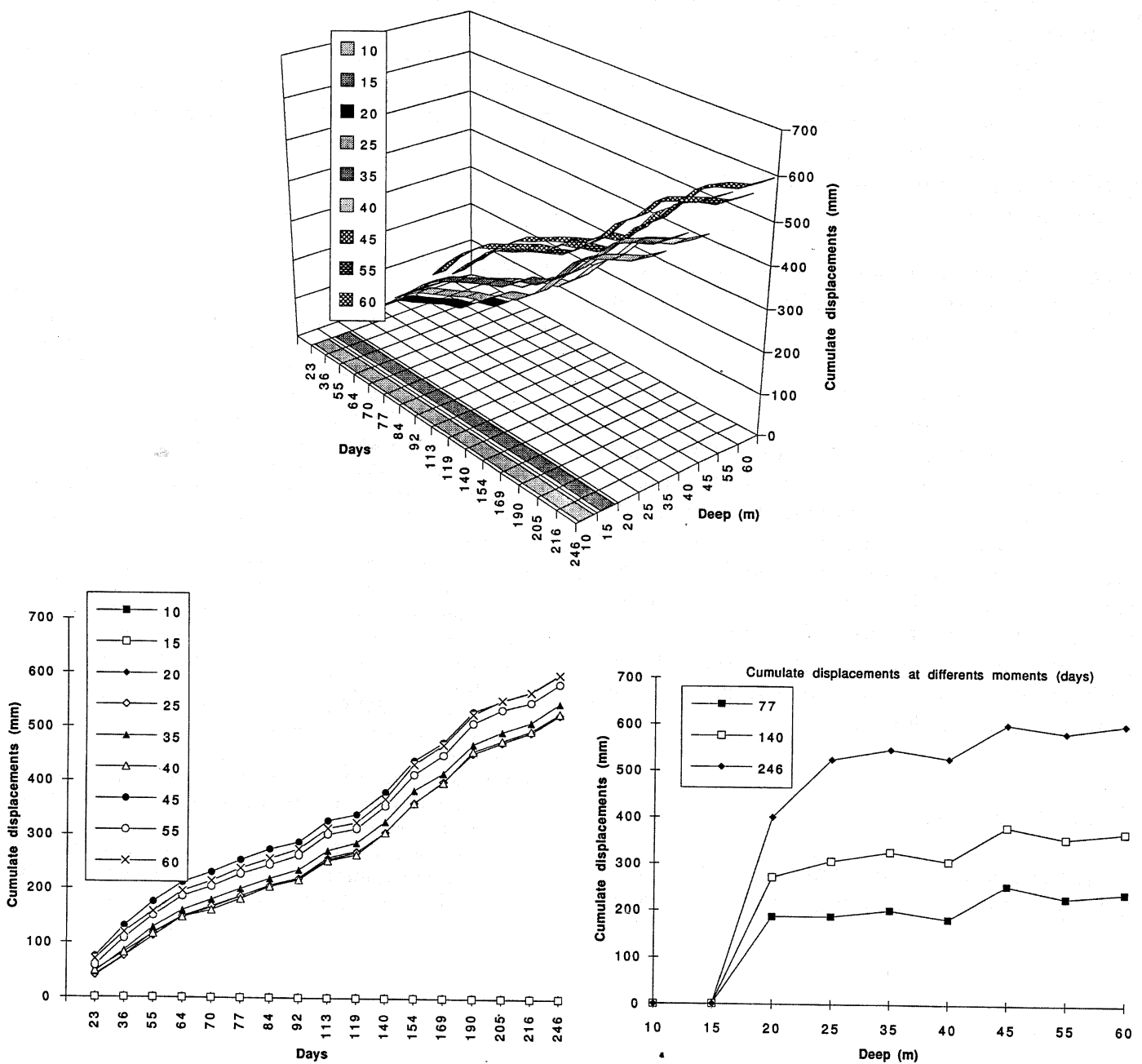

Fig. 4. Sketch of the elaboration of the multiple wire extensometer in borehole «S14». 
eventual inputting of the data from all the sensors is carried out on the basis of established storage criteria.

Operationally, values above threshold signal a state of alarm, of which three, with corresponding actions have been defined:

a) «state 0 »- sensor data is collected and stored at one-minute intervals. This sampling rate, determined on the basis of preliminary analysis and subject to modification, seems suitable for characterizing the long-term deformations in progress in the absence of any exceptional motive event. Thus, this represents the system's ordinary or «baseline» state of functioning.

b) «state $1 »-$ initiated when any single extensometric sensor, or combination thereof, signals deformation rates above threshold. The data acquisition rate automatically climbs to once per second per sensor.

c) «state 2 »-set off by a seismic (or sonic) event, even when minimal. The system records at the maximum projected rate of one reading per 0.001 second per sensor.

The system's hardware capacity enables it to be reset for sampling intervals other than those described above, and also allows sampling parameters to be changed according to any logical or mathematical relation among the various parameters measured by the different sensors. At present, for example, one criterion for initiation state 2 is an above-threshold reading in both geophones contemporaneously. The procedure aims to minimize local environmental noise effects, such as the passing of farm machinery near one of the surface geophones.

\section{Acquired data}

The checks and monitoring carried out to date, mainly through the inclinometer and exten- someter systems, have yielded a more precise determination of the effects of the action of ordinary forces on different portions of the slope. Figure 2 summarizes the data processing performed so far. A more specific example is furnished in fig. 4, which represents the results obtained from the multiple extensometer system installed in probe S14. It clearly shows the development of differential deformations between a superficial body of the landslide and a deeper slip surface. The slip surface of the former, deforming at a higher rate, lies at between 15 and 20 meters depth, while the lower is found at between 40 and 45 meters.

Ongoing experimentation with the real-time monitoring system is moreover providing the means to refine the control software and its as yet experimental components.

\section{REFERENCES}

Bruzzi, D., G. PezzetTi and S. Piccoli (1986): La strumentazione geotecnica nel monitoraggio dei movimenti franosi profondi, in Atti XVI Conv. Naz. Geot. A.G.I., Bologna, Vol. 1, pp. 153-164.

HANNA, T. H. (1985): Field instrumentation in geotechnical engineering (Trans Tech. Publications, FRG).

Pellegrino A., (1986): L'analisi dei movimenti franosi per la progettazione degli interventi di stabilizzazione (Relazione Generale), in Atti XVI Conv. Naz. Geot. A.G.I., Bologna, Vol. 3, pp. 121-150.

PILOT, G. (1984): Instrumentation and warning system for research and complex slope stability problems, in Atti «IV Int. Symp. on Landslides», Toronto, Vol. 1, pp. 275-306.

RIBACCHI, R. (1986): Il controllo della stabilità dei pendii (Relazione Generale), in Atti XVI Conv. Naz. Geot. A.G.I., Bologna, Vol.3, pp. 403-452.

SCHUSTER, R.L. and R.J. KRIZEK (Editors) (1978): Landslides analysis and control, Transportation research board, Special Rept. N. 176 (Nat. Acad. of Sciences).

VARNES, D.J. (1978): Slope movement types and processes, Transportation research board, Special Rept. N. 176 (Nat. Acad. of Sciences).

ZARUBA, Q. and V. MENCL (1982): Landslides and their control, Developments in geothecnical engineering (Elseviers Scient. Publ. Comp.), Vol. 31, II edition. 